\title{
In-vitro and in-vivo Consideration of Repaglinide Immediate-Release Tablet: Assessment of Porous Acetostarch as a Promising Carrier for Dissolution Rate Enhancement
}

\author{
Vivekanand K. Chatap*, Savita D. Patil \\ H R Patel Institute of Pharmaceutical Education and Research, Shirpur, Dist-Dhule, Maharashtra, 425405, India
}

Copyright $\bigcirc 2016$ by authors, all rights reserved. Authors agree that this article remains permanently open access under the terms of the Creative Commons Attribution License 4.0 International License

\begin{abstract}
Acetostarch was prepared using aqua-gel to an aceto-gel method and used as carrier to improved solubility and dissolution rate of Repaglinide (RPGD) to enhance oral bioavailability. The RPGD was selected as a model drug due to its low aqueous solubility and dissolution rate in GI fluid. In present research work, acetostarch was prepared by solvent exchange method and characterized by using FT-IR, DSC, XRPD, BET and FESEM studies followed by in-vitro drug release rate. In order to study drug interaction, compatibility, surface area, structural and morphological characteristics. Repaglinide loaded acetostarch (R-acetostarch) showed significant improvement in drug dissolution rate. Consequently, R-acetostarch immediate-release tablets were prepared by direct compression method. Pre and post-compression parameters for blend and tablets were studied and found within pharmacopoeial acceptable limits. R-acetostarch and immediate-release tablets demonstrated improved dissolution rate, when compared with pure crystalline RPGD,
\end{abstract} physical mixture and marketed tablets. The in-vivo assessment of R-acetostarch and immediate-release tablets were study by using oral glucose tolerance test and its indicated efficient control of blood glucose levels than pure RPGD and showed good in-vitro and in-vivo correlation. The results of stability studies revealed that there were no significant differences in physico-chemical parameters and dissolution rate between the initial and stored R-acetostarch immediate-release tablets. In a nutshell, it can be concluded that encapsulating poorly soluble drugs in porous acetostarch would be an innovative strategy for dissolution rate enhancement of BCS II drugs, when administered orally.

Keywords Repaglinide, Acetostarch, Sol-gel Method, Immediate-release Tablet, Dissolution Rate Enhancement, In-vitro and In-vivo Correlation

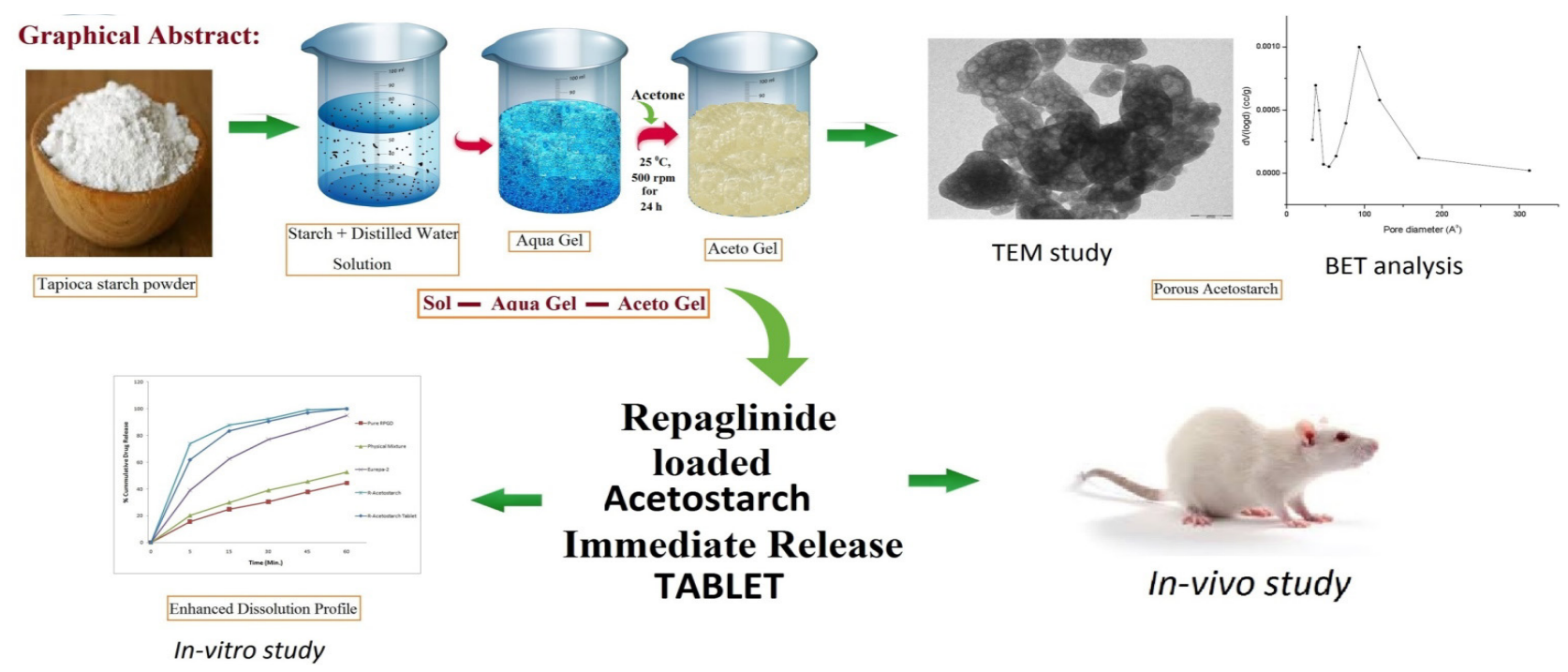




\section{Introduction}

Solubility, the phenomenon of dissolution of a solute in the solvent to obtain a homogenous system, is one of the essential parameters to attain desired concentration of drug in systemic circulation for desired pharmacological responses [1]. The low aqueous solubility is a major hurdle encountered with formulation development of new chemical entities as well as for the formulation development [2]. A large number of new drug discoveries have led to an increase in number of new drugs with low water solubility and hence poor bioavailability. Since approximately $65 \%$ of human body is made up from water the drug must have the aqueous solubility and acceptable level of bioavailability. Literature revealed that several techniques have been used for the enhancement of the solubility of poorly soluble drugs viz. micronization [3], nanonization [4], crystallization [5], supercritical fluid [6], spray drying [7], lyophilization, evaporative precipitation into aqueous solution [8], use of surfactant [9] and drug dispersion in carriers[10]. In recent year's utilization of inorganic and organic porous materials were explored for improving solubility, dissolution consequently enhanced the oral bioavailability of poorly water-soluble drugs.

Starch is a mixture of two polysaccharides, amylose and amylopectin that contains small amounts of non-carbohydrate constituents such as lipids, phosphates and proteins $[11,12]$. Tapioca starch is widely used because of its unique thickening properties, high purity, low cost, and ability to form clear viscous pastes. Unfortunately, it displays single functionality and low additional value in the industry, thus chemical and physical modifications are often made to overcome these problem and expand it used [13]. In recent years, modified starch was prepared using temperature and enzymatic based hydrolysis method. Modified starches were obtained from the different sources viz. corn, wheat (Triticumaestivum L.), rice (Oryza sativa L.), and potato (Solanumtuberosum L.) starch by partial hydrolysis with glucoamylase showed a higher gelatinization temperature than their native counterparts $[14,15]$. It has also been mention that starch foam shows excellent characteristics compared with inorganic carriers [16], owing to its distinctive advantages such as non-toxicity, biocompatibility, biodegradability $[17,18]$. Therefore the starch becomes the new and promising carrier for solubility and the dissolution rate enhancement of poorly water soluble drug. In the last decade, several scientists have been successfully prepared porous starch and starch-based polymers for many applications such as bone cement [19], nanoparticle [20], hydrogels [21], and tissue engineering scaffold [22]. However, porous starch is an attractive and promising carrier in a drug delivery research.

Repaglinide (RPGD) (2-ethoxy-4-[[3-methyl-1-[2-(1-piperidyl) phenyl]z -butyl] carbamoyl methyl ] benzoic acid) is a second generation oral hypoglycemic agent broadly used to treat type 2 diabetes mellitus [23]. RPGD belongs to BCS Class II, which comes within poorly soluble drugs having a number of limitations such as the need of higher dosage, the rise in administration frequency and consequential occurrence of side effects.

In the present investigation, an innovative attempt has been made to prepare porous an acetostarch using sol-gel method, owing to porous nature employed as a carrier for maximum drug loading and used to enhance the solubility and dissolution rate of Repaglinide. RPGD was selected as a model drug due to its low aqueous solubility and dissolution rate leads to poor bioavailability. R-acetostarch immediate-release tablets were prepared by direct compression method for oral administration and evaluated by different pre and post-compression parameters. In the view of cost effective utilization of natural resources, acetostarch may be a promising alternative carrier for solubility and dissolution profile enhancement of poorly water soluble drug.

\section{Experimental}

\subsection{Material}

Tapioca starch was purchased from Varlaxmi brand, Chennai, India. Repaglinide was received as a generous gift from Ajanta Pharmaceuticals Ltd. (Mumbai, India). Microcrystalline cellulose (Avicel PH101) and sodium starch glycolate, were procured from Research-lab fine chem industries, Mumbai, India. Talc and magnesium stearate were purchased from Loba Chemie Pvt. Ltd., Mumbai, India. All other chemicals and reagents used for the study were of analytical grade.

\subsection{Method}

\subsubsection{Sol-gel method}

Preparation of acetostarch was achieved using reported method with some modification[16]. In brief, accurately weighed quantity $(10 \mathrm{gm})$ of tapioca starch was dissolved in $110 \mathrm{~mL}$ double distilled water, heated to $100^{\circ} \mathrm{C}$ under constant stirring at 500rpm for $60 \mathrm{~min}$ using a magnetic stirrer (Remi Instruments Ltd, Mumbai, India). It resulted in the formation of homogeneous solution which was kept at $5^{\circ} \mathrm{C}$ for overnight to facilitate gelation. The resultant froze solution was converted into an aqua-gel at $25^{\circ} \mathrm{C}$, followed by an addition of $70,80,90$ and $100 \%$ ratio of acetone/water and stirred at $500 \mathrm{rpm}$ for $24 \mathrm{~h}$ using a magnetic stirrer in which acetone displaced the water in the aqua gel, leads to forming aceto-gel. The resultant aceto-gel was cast using specially designed novel mold [24] and dried at $30^{\circ} \mathrm{C}$ for $24 \mathrm{~h}$ using hot air oven (Pathak Elecrtical Works, Mumbai, India). Porous acetostarch was milled in a mortar, passed through standard mesh sieve \# $120(125 \mu \mathrm{m})$ and stored in a desiccators. 


\subsubsection{Preparation of physical mixture}

The physical mixture of RPGD/ acetostarch (1:3) was obtained by homogeneous mixing using mortar and pestle.

\subsubsection{Drug loading}

The drug loading was carried out using reported method [16]. The actual drug loading and drug content were determined using UV Spectrophotometer (Shimadzu-1800, Shimadzu Corp., Japan) at $243 \mathrm{~nm}$. All measurements were carried out in triplicate.

\subsubsection{Nitrogen adsorption/desorption analysis}

Nitrogen adsorption isotherm was obtained using Autosorb-6iSA surface area analyzer (Quantachrome, USA). In brief acetostarch powder sample $(0.0198 \mathrm{~g})$ was transferred to the sample bulb and evacuated to a pressure of $6.58 \mathrm{e}-051 / \mathrm{mmHg}$ at $30^{\circ} \mathrm{C}$ for $3.44 \mathrm{~h}$ to remove physically adsorbed water prior to analysis. The Brumauer-EmmetTeller specific surface area (BET-SSA) was estimated from the nitrogen adsorption data over a relative pressure $(\mathrm{P} / \mathrm{P} 0)$ range from 0.0 to 1.0 . The pore size diameter and pore volume were calculated by the Barrett-Joiner-Halenda (BJH) method [25] (Fig. 1)

\subsubsection{Surface morphology study}

\subsubsection{FESEM}

In FESEM study, the surface morphology of the pure sample and drug, acetostarch, physical mixture and drug loaded acetostarch was studied using a field emission scanning electron microscope (Hitachi S-4800 Type II scanning electron microscope, Japan). The sample was coated with gold using sputter coater and photomicrographs were captured by operating at an accelerating voltage of 10 $\mathrm{kV}$ electron beam (Fig.2)

\subsubsection{TEM}

The surface morphology of the samples was studied using Philips CM200 Transmission electron microscopy (Germany) operating at $20-200 \mathrm{kv}$ and capable of point-to-point resolution $2.4 \AA$, the combination of bright field imaging at increasing magnification and diffraction modes were used to reveal the form and size of acetostarch particles. In order to perform the TEM observations, made electrically conductive acetostarch by coating with a thin layer of gold by sputter coater Palaron E 5100. The dried coated grid was taken on a slide and covered with a cover slip. The slide was observed under the electron microscope [26] (Fig.3).

\subsubsection{FTIR}

The samples were studied for their functional group using Fourier transform infrared spectroscopy (FTIR, Shimadzu IR Affinity, Japan) in order to access interaction if any between drug and acetostarch in mixtures. The FTIR spectrum of pure RPGD was compared with spectra of acetostarch for any interactions (Fig.4).

\subsubsection{DSC}

The thermal behavior was assessed using differential scanning calorimetry (DSC, 822e, Mettler Toledo, Switzerland), acetostarch and R-acetostarch (Fig 5). The samples placed in an aluminum pan and crimped using a press. Empty aluminum pan placed as a reference. DSC studies were performed at a heating rate of $10^{\circ} \mathrm{C} / \mathrm{min}$ from a range of 40 to $300^{\circ} \mathrm{C}$ in an inert atmosphere.

\subsubsection{XRPD}

$\mathrm{X}$-ray diffraction (XRD) studies were done to determine the solid form of samples using X-ray diffractometer (Bruker AXS, D8 Advance, Germany) with $\mathrm{Cu}-\mathrm{K} \alpha$ radiation source. The XRPD was operated at the voltage $40 \mathrm{kV}$ and current 30 $\mathrm{mA}$. The samples were measured in the $2 \theta$ angle with a most informative range between 100 and 600 and a scanning rate of $2^{\circ} \mathrm{min}^{-1}$ with a step size of $0.02^{0}$ (Fig 6).

\subsection{Preparation of $R$-acetostarch Immediate-release Tablet}

The R-acetostarch immediate-release tablets were prepared using direct compression method according to the previously reported study [27]. Weighed accurately R-acetostarch (equivalent RPGD 2 mg dose), Avicel PH101, sodium starch glycolate, aerosil and magnesium stearate and manually mixed in the ratio of concentrations $(5: 1: 1 \% \mathrm{w} / \mathrm{w})$ respectively for the total weight $100 \mathrm{mg}$ per tablet and total 100 tablets were compressed. The tablets were prepared using 12-station tablet compression machine (Mini Press II, Karnavati, Gujarat, India) fitted with $8 \mathrm{~mm}$ round punches without bisection line.

\subsection{Pre and Post-compression Studies of R-acetostarch Immediate-release Tablet}

The flow property of mixture blends was characterized by measurement of powder flow rate for preparation of R-acetostarch immediate-release tablets. The \%compressibility and Hausner ratio was calculated from the values tapped and bulk density. The compressed $\mathrm{R}$-acetostarch immediate-release tablets were evaluated by weight variation, hardness, friability and disintegration time test parameters [28], and shown in (Table 1).

\subsection{In-vitro Dissolution Studies}

The in-vitro drug release study was carried out with reported dissolution study [29]. In details, the pure RPGD, physical mixture, R-acetostarch powder (equivalent to $4 \mathrm{mg}$ of Repaglinide), commercially marketed tablet (Eurepa-2) and R-acetostarch prepared immediate-release tablets were studied using dissolution test apparatus II USP (Dissolution test TDT-08Lx, Electrolab, India) in $500 \mathrm{~mL}$ of $0.1 \mathrm{~N} \mathrm{HCl}$, $\mathrm{pH} 1.2$ at $37 \pm 0.1^{\circ} \mathrm{C}$, and stirred at $75 \mathrm{rpm}$ paddle speed with sink condition. Aliquot $5 \mathrm{~mL}$ samples at $15 \mathrm{~min}$ intervals and 
filtered through $0.45 \mu \mathrm{m}$ Millipore filter. The samples were analyzed by UV spectrophotometer at $243 \mathrm{~nm}$ (Fig. 5).

\subsection{Stability Studies}

The prepared R-acetostarch immediate-release tablets were placed in the stability test chamber and subjected to stability studies at accelerated testing conditions $(40 \pm$ $\left.2{ }^{\circ} \mathrm{C} / 75 \pm 5 \% \mathrm{RH}\right)$ for 3 months according to $\mathrm{ICH}$ guidelines [30]. The evaluation parameters for immediate-release tablets were checked as follows physical appearance, hardness and friability and disintegration time, drug content and in-vitro dissolution studies at the interval of a month during stability study (Table 2).

\subsection{In-vivo Study (Antihyperglycemic Activity)}

The experimental protocol for animal studies was approved by institutional ethical committee of R.C. Patel institute of pharmaceutical education and research, Shirpur, India, as per the guidance of committee for the purpose of control and supervision of experiments on animals (registration no. IAEC/RCPIPER/2015-16/26). Healthy Wistar rats of 3 to 4 months old, in the weight range of 150 $250 \mathrm{~g}$ were used for the antihyperglycemic activity. The animals were housed in cages in groups at reported standard environmental condition ( $12 \mathrm{~h}$ dark-light cycle, $25 \pm 30^{\circ} \mathrm{C}$, $35-60 \%$ humidity), feed with commercial pellet diet, tap water ad libitum. The oral glucose tolerance test (OGTT) was performed as per reported method [31].The rats were divided into three groups $(\mathrm{n}=6)$ and kept in fasted condition at overnight for $16 \mathrm{~h}$. Group I served as control, Group II with pure RPGD $(66.66 \mu \mathrm{g} / \mathrm{kg})$ and Group III with prepared R-acetostarch immediate-release tablet $5 \mathrm{~min}$. The glucose load $3 \mathrm{~g} / \mathrm{kg}$ was in all groups of an animal through oral route and blood glucose levels were reached peak at 60 min [32]. The blood samples were withdrawn from the retro-orbital sinus under ether inhalation after $0,60,90$ and $120 \mathrm{~min}$. The blood glucose levels $(\mathrm{mg} / \mathrm{dL})$ were determined immediately using a glucose assay kit and plotted graph as amount reduction in blood glucose level versus function of time.

\subsection{Statistical Analysis}

The experimental data were calculated and analyzed using one-way analysis of variance (ANOVA) followed by Bonferroni's multiple comparison tests [33]. The values of $\mathrm{p}<0.05$ were measured statistically significant and expressed as mean $\pm \mathrm{SD}$ of blood glucose level values of control, pure RPGD and prepared R-acetostarch immediate-release tablet.

\section{Results and discussion}

\subsection{Sol-gel Method}

The preparation of porous acetostarch was achieved using reported sol-gel method. The 90\%ratio acetone/water was found greater acetone displaced with water leads to conversion of aqua-gel to aceto-gel and to maintain porous structure due to subsequent air dried process. It is obvious that acetone has a lower surface tension than water and does not solubilize starch and can be readily volatilized. It was found that during the preparation of an acetostarch optimum temperature of $85^{\circ} \mathrm{C}$ and $10 \%$ concentration of the aqueous starch solution was found to be effective.

\subsection{Drug Loading}

The pure RPGD was loaded in acetostarch via adsorption equilibrium with solvent evaporation method[16]. Results revealed that the ratio of 1:3 w/w (RPGD: Acetostarch) was found to be very effective as it resulted in accurate $25 \%$ drug loading when to compare with another ratio. The drug adsorbed and diffused into the porous inorganic material by capillary effects at the gas-liquid menisci in the pore throats.[34]. However, the ratio of drug loading increasing beyond the optimized ratio $1: 3(\mathrm{w} / \mathrm{w})$ results in deposition of crystalline drug molecules outer surface the pores [35].

\subsection{BET Analysis}

Nitrogen adsorption-desorption was obtained using a Autosorb-6iSA surface area analyzer (Quantachrome, USA). The acetostarch sample exhibited a type IV isotherm[36], characteristic of porous materials. The adsorption branch of the isotherm is steep and an H1 type hysteresis loop was observed. As shown in Fig.1 BJH Desorption method was used for determination of pore diameter, pore volume and was found to be $93.27 \mathrm{~A}^{0}$ and $0.056 \mathrm{cc} / \mathrm{g}$ respectively. The pore diameter $\mathrm{Dv}(\mathrm{d})$ of porous acetostarch is between that of mesopores and large pores. The Brumauer-Emmet-Teller specific surface area (BET-SSA) was found to be $22.460 \mathrm{~m}^{2} / \mathrm{g}$. 

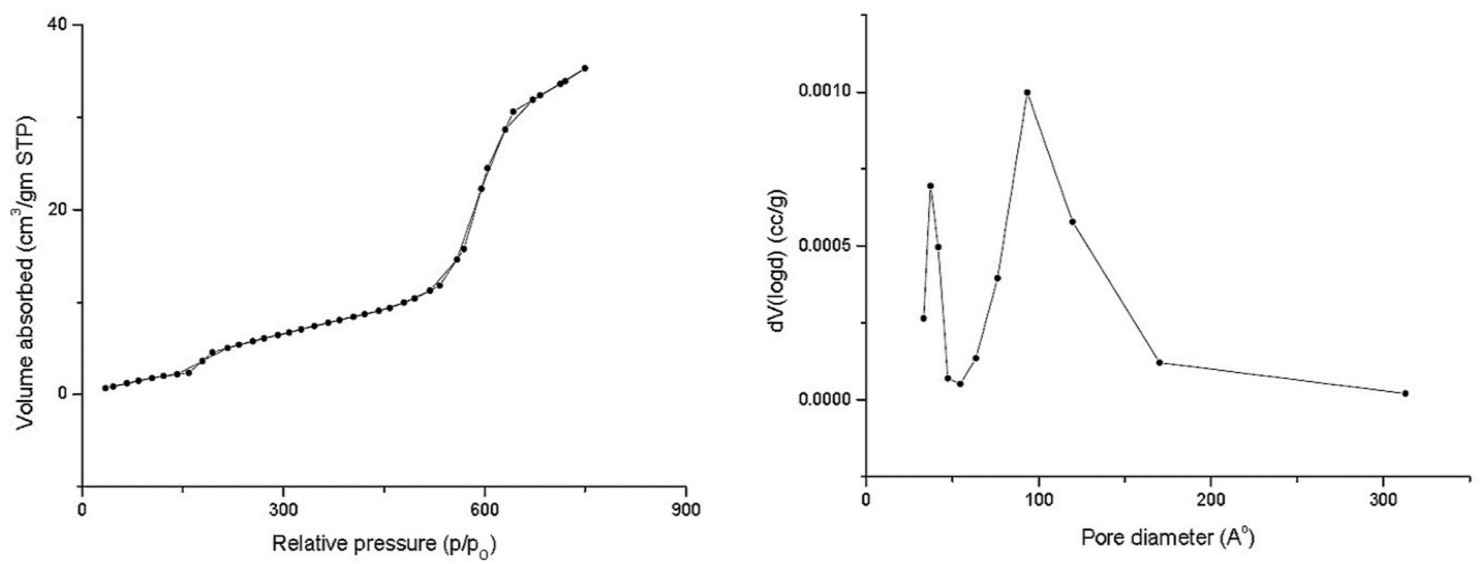

Figure 1. The pore size diameter and pore volume

\subsection{FESEM}

The surface morphology of the prepared an acetostarch (B), R-acetostarch(D) physical mixture(C) and pure drug RPGD (A) was studied using a FESEM. It was observed that needle shape crystals of RPGD were observed in pure RPGD sample as well as a physical mixture (Fig.2A, 2C). The FESEM images of porous acetostarch (B) disorders of pores appear in acetostarch (Fig.2B, 2D) and disappear of pores found in RPGD loaded acetostarch. However, it was clearly indicated that RPGD was successfully loaded in porous acetostarch as a drug was absorbed into the pores from different directions and this simultaneously reduces the diffusional resistance of drug in the porous channels.
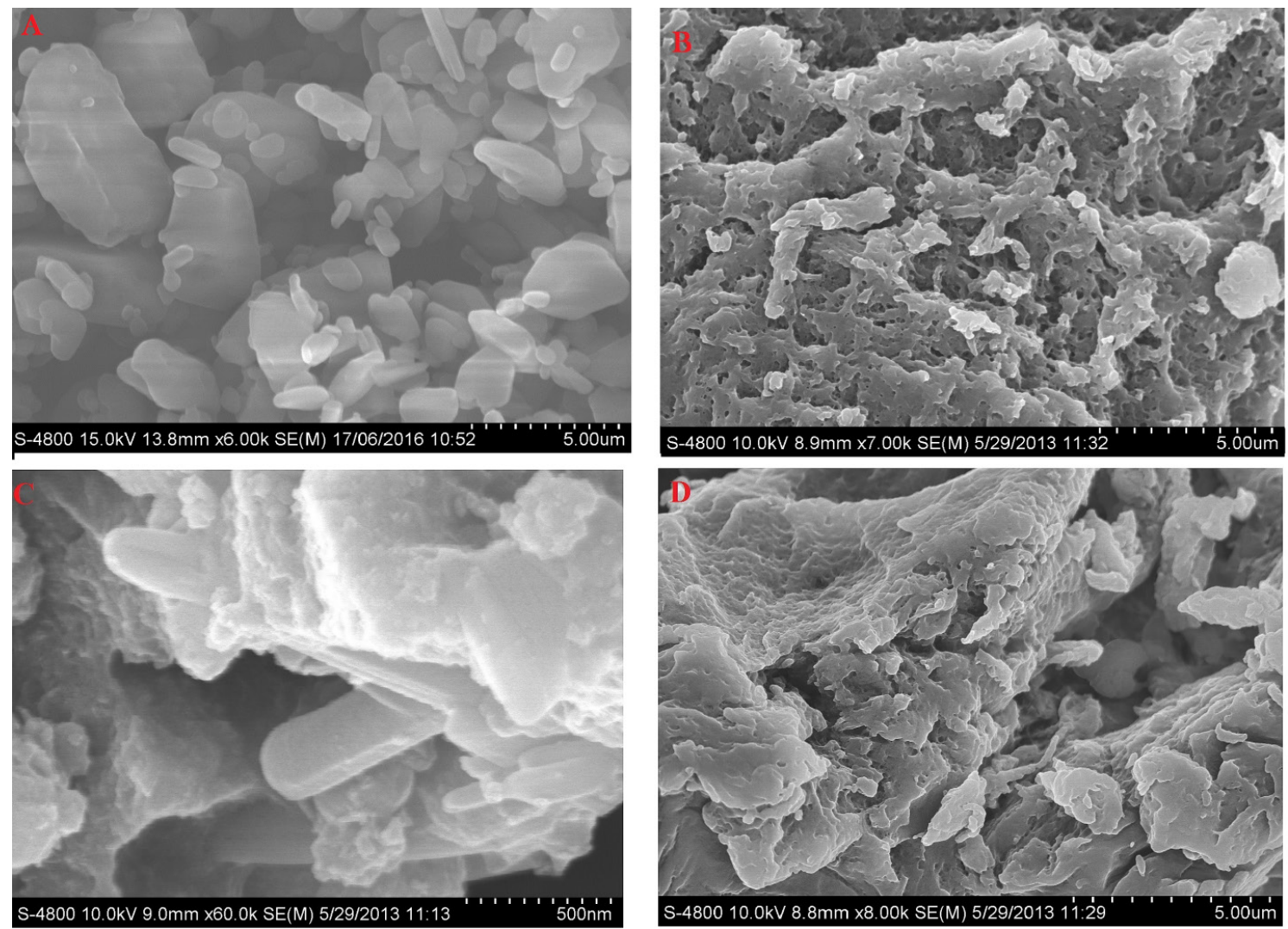

Figure 2. FESEM images of (A) RPGD (B) Acetostarch (C) physical mixture and (D) R-acetostarch

\subsection{TEM}

The surface morphology of the fabricated porous acetostarch was studied using TEM at 200nm. The samples of acetostarch showed porous structure (nature) of acetostarch (Fig. 3) 


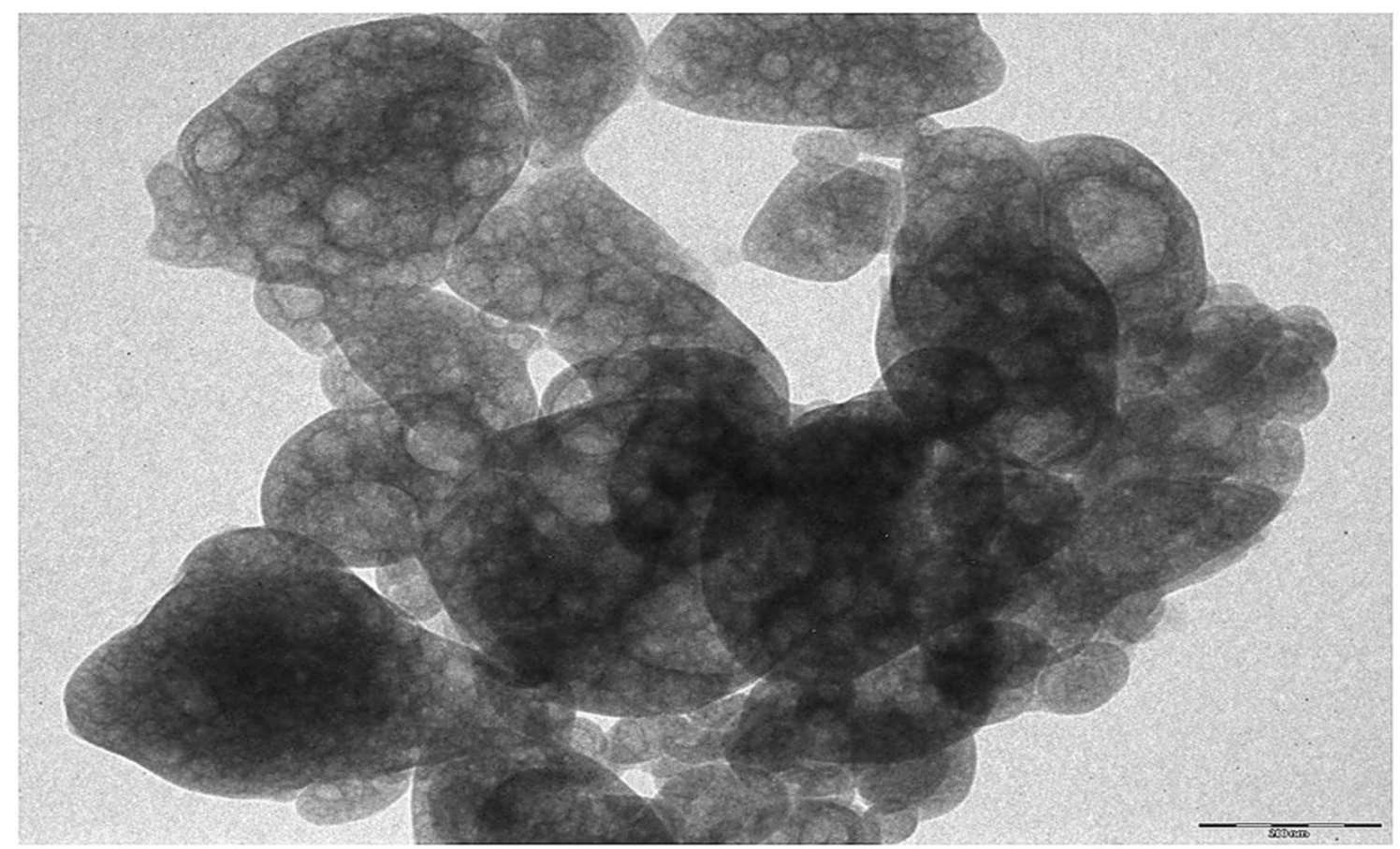

Figure 3. TEM images of acetostarch

\subsection{FT-IR}

FT-IR spectra of pure RPGD which is characterized by carbonyl peaks at $\left(1688.75 \mathrm{~cm}^{-1}\right), \mathrm{C}-\mathrm{H}$ group $\left(2935.90 \mathrm{~cm}^{-1}\right)$ and NH $\left(3310.95 \mathrm{~cm}^{-1}\right.$ ) stretching (Fig. 4). All the characteristic peaks of pure RPGD were found drastically reduced and present at same wave number in the spectra of the physical mixture, which indicate that drug dispersed molecularly in a carrier and had no modification or interaction between the drug and porous acetostarch was found. For a better understanding of interaction if any, all samples were recorded separately. The broad characteristics peaks at 2957.10 and $3315.74 \mathrm{~cm}^{-1}$ showed a hydrophilic surface with lots of hydrophilic hydroxyl groups $(-\mathrm{OH})$ present in a porous acetostarch. The spectra of R-acetostarch revealed identical peaks of the carboxyl group $(\mathrm{C}=\mathrm{O})$ at $1624.21 \mathrm{~cm}^{-1}, \mathrm{NH}$ and $\mathrm{C}-\mathrm{H}$ group was disappeared from his peak wave number or shifted $1640.53 \mathrm{~cm}^{-1}$ and $2930.96 \mathrm{~cm}^{-1}$ respectively When the spectra of R-acetostarch was compared with other samples. All the characteristic peaks of pure RPGD were found either disappeared or drastically reduced, thus indicates the entrapment of RPGD in porous acetostarch[37].

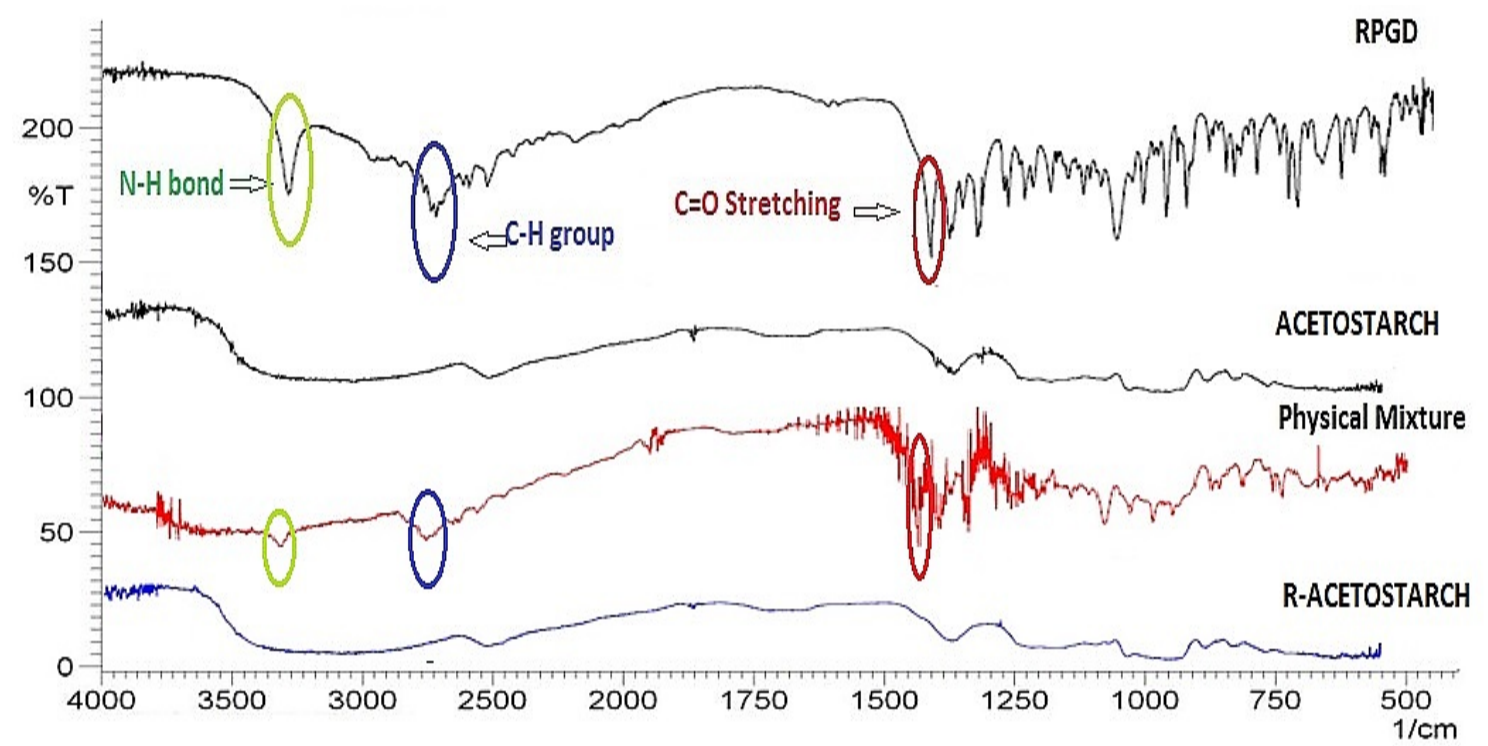

Figure 4. FTIR spectra of A) RPGD B) Acetostarch C) Physical Mixture D) R-acetostarch 


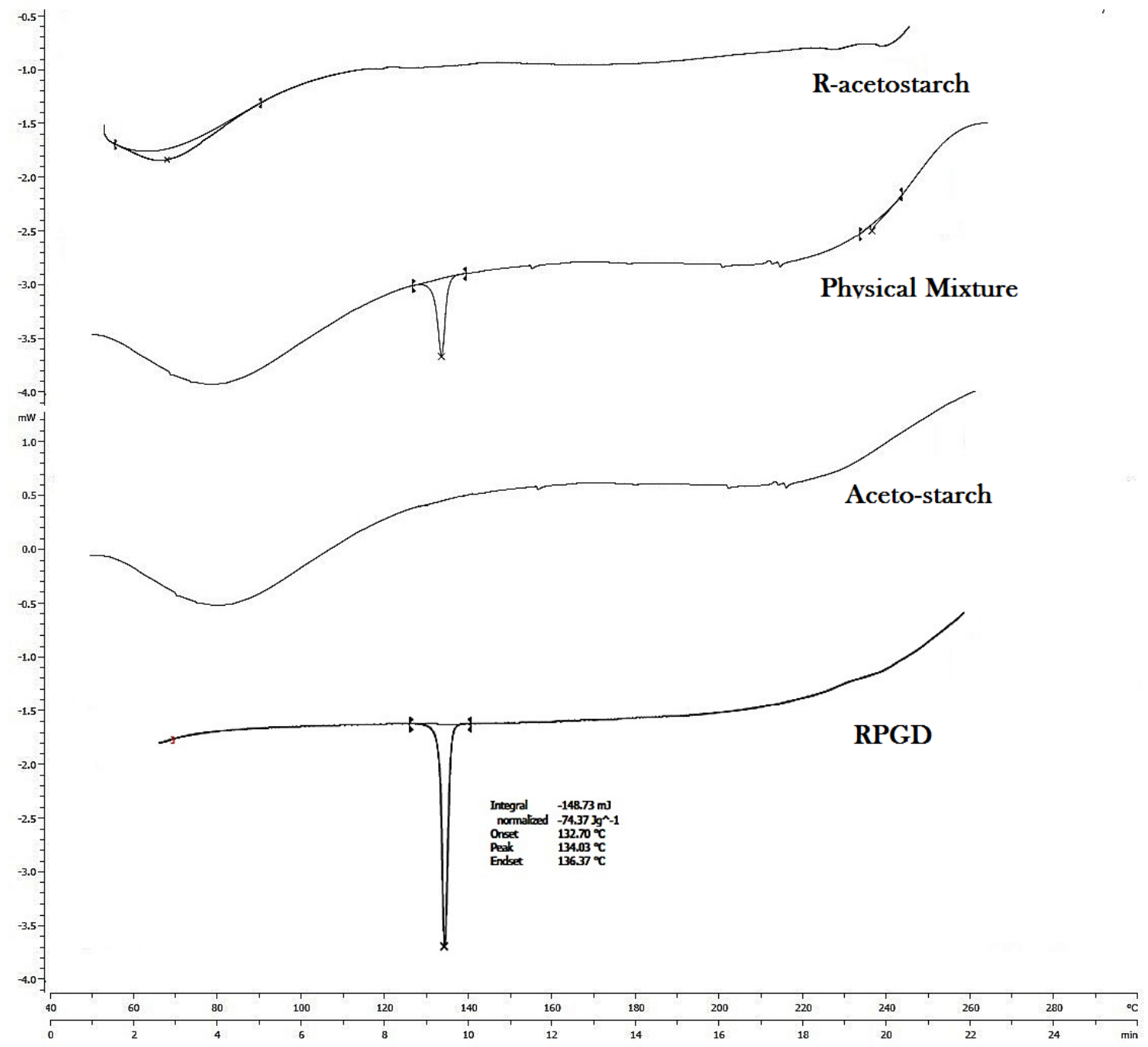

Figure 5. DSC thermogram of A) RPGD B) Acetostarch C) Physical Mixture D) R-acetostarch

\subsection{DSC}

The possible interaction and stability between pure RPGD and acetostarch were determined by DSC. Fig.5A showed a sharp melting endothermic peak at $138^{\circ} \mathrm{C}$ of pure RPGD, which indicates crystalline nature of drug and peak value was found in accordance with the previously reported studied. The porous acetostarch showed (Fig.5B) shallow endothermic peak at $80.78^{\circ} \mathrm{C}$, which indicates loss of water. Fig. $5 \mathrm{C}$ revealed the intensity of an endothermic peak at $138^{\circ} \mathrm{C}$ was drastically reduced in physical mixture pure RPGD with acetostarch. This may be due to partial loss of crystalline nature of drug during the homogeneous mixing. R-acetostarch (Fig.5D) indicates the endothermic peak at $80.78,138^{\circ} \mathrm{C}$ of porous acetostarch and pure RPGD was disappeared due to drug effectively loaded in porous acetostarch which revealed the structure of pure RPGD convert from crystalline to amorphous nature.

\subsection{XRPD}

The polymorphic changes in drug directly affect on dissolution rate and oral bioavailability [1]. Hence, it is important to study polymorphic changes in pure RPGD. Fig.6A revealed sharp peaks at diffraction angles $(2 \theta)$ of pure RPGD at $7.6^{\circ}, 9.9^{\circ}, 13^{\circ}, 16.5^{\circ}, 20.1^{\circ}, 22.6^{\circ}$, and $30.5^{\circ}$ which, indicated crystalline nature of drug and Fig.6B XRPD pattern of acetostarch showed single shallow peaks at $22.10^{\circ}$ results to indicated the amorphous nature of porous acetostarch. Fig.6C, the XRPD spectra of the physical mixture showed the reduction in the intensity of prominent sharp characteristic diffraction peaks of RPGD due to partial loss of crystalline nature of drug during homogeneous mixing in a mortar. In Fig.6D characteristic diffraction peaks of pure RPGD were completely disappeared from XRPD spectra of R-acetostarch due to effectively drug loaded in porous acetostarch, which indicates the transformation of RPGD from crystalline state to amorphous state. Thus, the result of XRPD supports the findings of the FTIR and DSC study. 


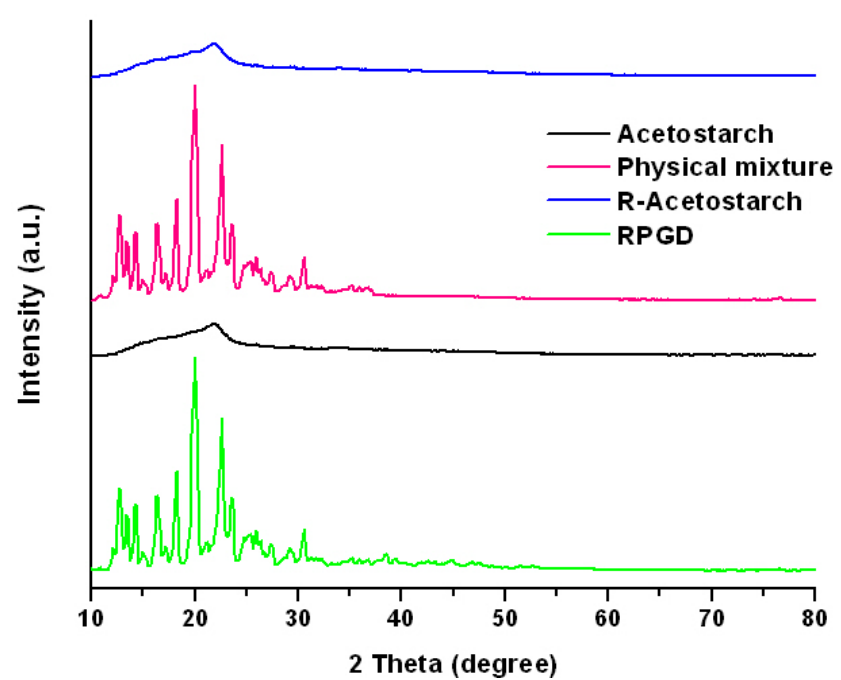

Figure 6. XRPD diffractogram of A) RPGD B) acetostarch C) Physical Mixture D) R-acetostarch

\subsection{Preparation of R-acetostarch Immediate-release Tablet}

R-Acetostarch immediate-release tablets were prepared by reported direct compression method due to its industrial applicability. Immediate-release tablet contains a mixture of avicel PH101, sodium starch glycolate, aerosil and R-acetostarch (2 $\mathrm{mg}$ equivalent dose) that revealed maximum in- vitro drug release in short time.

\subsection{Evaluation of Pre and Post-compression Parameters}

The pre-compression parameters play an important role in flow property of powder blends for a compressed tablet. The bulk density and the tapped density values were found to be a $0.666 \mathrm{~g} / \mathrm{mL}$ and $0.730 \mathrm{~g} / \mathrm{mL}$ respectively, which revealed that the powder blends have good flow properties. The carr's index, Hausner ratio and angle of repose are the trial of the propensity of a powder to be compressed, which reflects the inter-particle friction resistance to movement between particles. The powder flowability of R-acetostarch immediate-release tablets blend was determined using carr's index and Hausner ratio and was found to be $8.824 \%, 1.097$ and $31^{\circ}$ respectively and revealed free flow property of blends. The weight uniformity test was carried out prepared tablets and found average weight deviation from the range of $0.85-1.5 \%$. Thus, reflects proper mixing and good flowability of the blend which leads complete filling of dies during compression of a tablet. The friability of $\mathrm{R}$-acetostarch immediate-release tablets was found to be below $1 \%$ ensuring that tablets mechanically stable without any change in surface hardness. The hardness and disintegration time of tablet was found $4.3 \mathrm{~kg} / \mathrm{cm}^{2}$ and 80 seconds, which demonstrated faster dissolution of the drug in dissolution media. The results are summarized in Table 1 . Results of the study indicated that the pre and post-compression parameters of R-acetostarch immediate-release tablet were found in accordance with the pharmacopoeial acceptable limits.

Table 1. Pre and post-compression results of formulation blend and R-acetostarch immediate release tablet

\begin{tabular}{|c|c|}
\hline Parameters & Results \\
\hline Bulk density (g/mL) & 0.666 \\
\hline Tapped density (g/mL) & 0.730 \\
\hline Carr's index (\%) & 8.824 \\
\hline Hausner's ratio & 1.097 \\
\hline Angle of repose ( $\boldsymbol{\theta})$ & $31^{0}$ \\
\hline Disintegration time (sec.) & 85 \\
\hline Weight variation (mg) & $100 \pm 1.5$ \\
\hline Friability (\%) & $0.45 \pm 0.01$ \\
\hline Hardness (kg/cm $\mathbf{~})$ & $4.3 \pm 0.006$ \\
\hline
\end{tabular}

Mean \pm SD, $n=3$

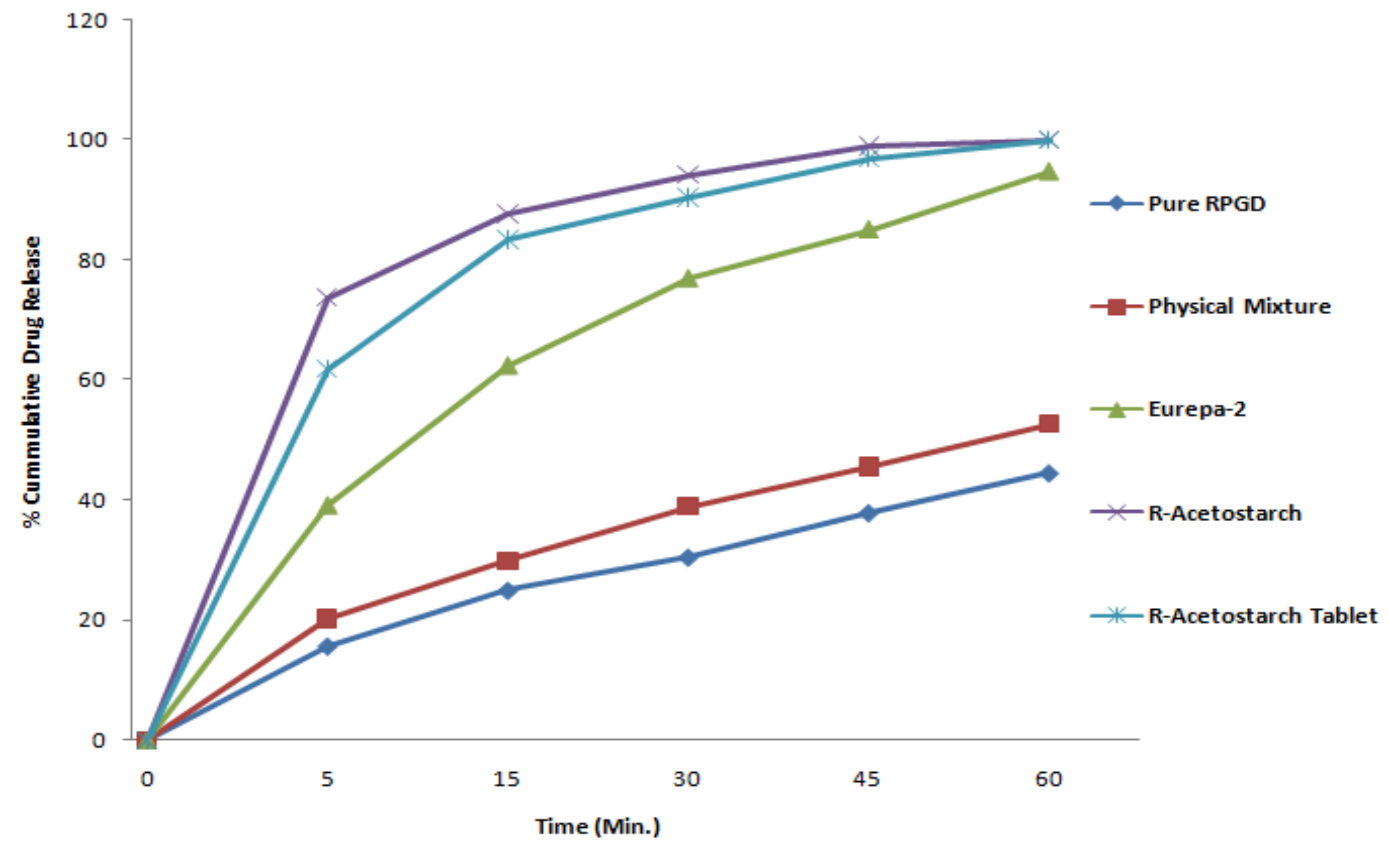

Figure 7. In-vitro dissolution studies 


\subsection{In-vitro Dissolution Studies}

The In-vitro dissolution study was carried as per reported method. In Fig.7 drug-release rate of R-acetostarch powder, $\mathrm{R}$-acetostarch immediate-release tablet and commercial tablet were found $94.25 \%, 90.48 \%$ and $76.98 \%$ respectively and compared with the physical mixture and pure crystalline RPGD30.43\% and $38.98 \%$ after 30 minutes. The dissolution rate of drug loaded porous acetostarch and R-acetostarch immediate-release tablet was increased due to the specific surface area of an acetostarch was improved during drying of aceto-gel in hot air oven at $30^{\circ} \mathrm{C}$. The wetting time and dissolution rate were increased due to a particle size of incorporated drug into the pore channels acetostarch found in nanometer scale range and changes in a solid state of pure RPGD from an amorphous to crystalline state [38].

\subsection{Stability Study}

The stability study of R-acetostarch immediate-release tablet was carried out as per the ICH guidelines and investigates the effect of aging on physico-chemical parameters and dissolution rate of $\mathrm{R}$-acetostarch immediate-release tablet. The physical appearance, hardness, friability, disintegration time, drug content, and dissolution rate were measured at one-month intervals. The results revealed that there was no significant difference between the initial and stored R-acetostarch immediate-release tablets found in physico-chemical parameters and dissolution rate (Table 2).

Table 2. Stability study of R-acetostarch immediate release tablet for 3 months.

\begin{tabular}{|c|c|c|c|c|}
\hline \multirow{2}{*}{ Parameters } & \multicolumn{4}{|c|}{ stability study at $40 \pm 2{ }^{\circ} \mathrm{C} / 75 \pm 5 \% \mathrm{RH}$} \\
\cline { 2 - 5 } & 0 & 1 & 2 & 3 \\
\hline $\begin{array}{c}\text { Appearance } \\
\text { (color) }\end{array}$ & white & white & white & white \\
\hline $\begin{array}{c}\text { Hardness } \\
\left(\mathrm{gm} / \mathrm{cm}^{3}\right)\end{array}$ & $4.3 \pm 0.006$ & $4.4 \pm 0.012$ & $4.4 \pm 0.011$ & $4.4 \pm 0.011$ \\
\hline Friability (\%) & $0.45 \pm 0.01$ & $0.42 \pm 0.02$ & $0.41 \pm 0.02$ & $0.41 \pm 0.02$ \\
\hline $\begin{array}{c}\text { Disintegration } \\
\text { time (Sec.) }\end{array}$ & 85 & 86 & 87 & 87 \\
\hline $\begin{array}{c}\text { Drug content } \\
(\%)\end{array}$ & $100 \%$ & $100 \%$ & $100 \%$ & $100 \%$ \\
\hline $\begin{array}{c}\text { Dissolution } \\
\text { rate (\%) }\end{array}$ & $90.48 \%$ & $89.87 \%$ & $89.69 \%$ & $89.72 \%$ \\
\hline
\end{tabular}

\subsection{In-vivo Study (Antihyperglycemic activity)}

The R-acetostarch immediate-release tablet showed stable and faster drug release as compared to pure RPGD; hence tablets were selected for in-vivo study using oral glucose tolerance test. RPGD as an oral hypoglycemic agent, which acts on a beta cell to increase insulin secretion leads to decreases the blood glucose level. Accordingly, the blood glucose level was monitored and was taken as an evaluation parameter for of the in-vivo study of R-acetostarch immediate-release tablet and compared with pure RPGD.
The antihyperglycemic activity was performed on the basis of its ability to prevent the elevated blood glucose levels after administration of glucose load. Increased rate of drug dissolution owed to increase oral bioavailability and in turn the pharmacological response [31]. Thus, pure RPGD and tablet formulation were administered orally. The results in Table. 3 revealed that blood glucose level after 60,90 and $120 \mathrm{~min}$ of orally administered R-acetostarch immediate-release tablet and pure RPGD was found to be $98 \pm 1.870,87 \pm 1.673,82 \pm 1.048$ and $108 \pm 2.880,100 \pm 2.316$, $92 \pm 2.658 \mathrm{mg} / \mathrm{dL}$, respectively. The result of R-acetostarch immediate-release tablet was found to statistically significant. These results revealed that acetostarch owing to its porous nature would a promising carrier due to its significant hypoglycemic effect. This significant result was found due to improved solubility and dissolution of drug which would lead to faster absorption and thus improved the bioavailability of RPGD. These results confirm in-vitro and in-vitro correlation.

\section{Conclusions}

Porous acetostarch was prepared using a sol-gel method and used to overcome the limitation of poor solubility of RPGD and to improve its dissolution in gastric conditions. The RPGD was successfully loaded in porous acetostarch with optimum drug loading. The prepared acetostarch was found to be porous in nature and it was evident by BET analysis. Furthermore, surface morphology study using FESEM and TEM revealed porous nature of acetostarch. The FTIR, DSC and XRPD studies proved that RPGD was uniformly dispersed and absorbed in porous acetostarch and changed from crystalline to amorphous state, represent it as an excellent drug carrier. R-acetostarch immediate-release tablets were prepared by direct compression method. Pre and post-compression parameters for blend and tablets were studied and found within pharmacopoeial acceptable limits. $\mathrm{R}$-acetostarch and R-acetostarch immediate-release tablet showed greatly improved dissolution rate, when compared with pure crystalline RPGD, physical mixture and commercially marketed tablet. The in-vivo studies of tablet indicated effective control of rising in blood glucose levels than pure RPGD and showed good in-vitro and in-vivo correlation. The results of stability studies revealed that there were no significant differences in physico-chemical parameters and dissolution rate between the initial and stored R-acetostarch immediate-release tablets.

Hence, form the promising results as discussed above, we lead to the conclusion that the porous acetostarch is a potential carrier for oral delivery of poorly water soluble drugs like RPGD, due to enhanced solubility, dissolution rate. This carrier system may demonstrate improved oral bioavailability, cost effectiveness, industrial applicability and holds a huge potential for being commercialized in the field of the pharmaceutical formulation in near future. 
Table 3. Time course of blood glucose levels in all groups

\begin{tabular}{|c|c|c|c|c|}
\hline \multirow{2}{*}{ Groups / Treatment } & \multicolumn{4}{|c|}{ Blood glucose (mg/dL) } \\
\cline { 2 - 5 } & 0 min. & $60 \mathrm{~min}$. & $90 \mathrm{~min}$. & $120 \mathrm{~min}$. \\
\hline Group-I (control) & $82 \pm 2.483$ & $152 \pm 1.414$ & $136 \pm 2.588$ & $122 \pm 2.316$ \\
\hline Group-II (pure RPGD) & $84 \pm 1.471$ & $108 \pm 2.880^{(\mathrm{a})}$ & $100 \pm 2.316^{(\mathrm{a})}$ & $92 \pm 2.658^{(\mathrm{a})}$ \\
\hline $\begin{array}{c}\text { Group-III (R- acetostarch } \\
\text { immediate- release tablet) }\end{array}$ & $81 \pm 1.329$ & $98 \pm 1.870^{\left(\mathrm{b}^{*}\right)}$ & $87 \pm 1.673^{\left(\mathrm{c}^{*}\right)}$ & $82 \pm 1.048^{\left(\mathrm{c}^{*}\right)}$ \\
\hline
\end{tabular}

Value are mean \pm S.E. animals each group (n=6) a) $p<0.001$ vs. control, b) $p<0.01$ vs. control, c) $p<0.05$ vs. control a*) $p<0.01$ vs. pure RPGD, b $\left.^{*}\right) p<0.01$ vs. pure RPGD and $\left.\mathrm{c}^{*}\right) p<0.05$ vs. pure RPGD

\section{Acknowledgements}

Authors would like to thank North Maharashtra University, Jalgaon and IIT Mumbai, for carried out FESEM, XRD \& TEM facilities. The authors are grateful to Mr. Pankaj Kadam, Sr. Executive, Analytical Instruments Dept. Quantachrome, USA for carrying out BET analysis from IIT Kanpur. The authors are also thankful to Ajanta Pharmaceuticals Ltd. (Mumbai, India) for providing gift samples of RPGD. Authors are also grateful to principal, $\mathrm{H}$. R. / R.C. Patel Institute of Pharmaceutical Education and Research for providing all the necessary facilities and infrastructure to carry out this study.

\section{Conflict of Interest}

No conflicts of interest.

\section{REFERENCES}

[1] Savjani, K.T., A.K. Gajjar, and J.K. Savjani, Drug solubility: importance and enhancement techniques. ISRN pharmaceutics, 2012. 2012.

[2] Kumar, S., et al., Novel Approaches for Enhancement of Drug Bioavailability. Reviews in Advanced Sciences and Engineering, 2013. 2(2): p. 133-154.

[3] Vogt, M., K. Kunath, and J.B. Dressman, Dissolution enhancement of fenofibrate by micronization, cogrinding and spray-drying: comparison with commercial preparations. European Journal of Pharmaceutics and Biopharmaceutics, 2008. 68(2): p. 283-288.

[4] Chen, H., et al., Nanonization strategies for poorly water-soluble drugs. Drug Discovery Today, 2011. 16(7): p. 354-360.

[5] Gao, P., et al., Enhanced Oral Bioavailability of a Poorly Water Soluble Drug PNU - 91325 by Supersaturatable Formulations. Drug development and industrial pharmacy, 2004. 30(2): p. 221-229.

[6] Mishima, K., Biodegradable particle formation for drug and gene delivery using supercritical fluid and dense gas. Advanced Drug Delivery Reviews, 2008. 60(3): p. 411-432.

[7] $\mathrm{Hu}, \mathrm{J}$. , et al., Continuous and scalable process for water-redispersible nanoformulation of poorly aqueous soluble APIs by antisolvent precipitation and spray-drying. International journal of pharmaceutics, 2011. 404(1): p.
198-204.

[8] Vaughn, J.M., et al., Supersaturation produces high bioavailability of amorphous danazol particles formed by evaporative precipitation into aqueous solution and spray freezing into liquid technologies. Drug development and industrial pharmacy, 2006. 32(5): p. 559-567.

[9] Granero, G.E., C. Ramachandran, and G.L. Amidon, Dissolution and solubility behavior of fenofibrate in sodium lauryl sulfate solutions. Drug development and industrial pharmacy, 2005. 31(9): p. 917-922.

[10] Gupta, M.K., et al., Enhanced drug dissolution and bulk properties of solid dispersions granulated with a surface adsorbent. Pharmaceutical development and technology, 2001. 6(4): p. 563-572.

[11] Buléon, A., et al., Starch granules: structure and biosynthesis. International journal of biological macromolecules, 1998. 23(2): p. 85-112.

[12] Jenkins, P. and A. Donald, The influence of amylose on starch granule structure. International Journal of Biological Macromolecules, 1995. 17(6): p. 315-321.

[13] Chen, Y., et al., Manganese oxide-based multifunctionalized mesoporous silica nanoparticles for pH-responsive MRI, ultrasonography and circumvention of MDR in cancer cells. Biomaterials, 2012. 33(29): p. 7126-7137.

[14] Zhang, B., et al., Corn porous starch: Preparation, characterization and adsorption property. International journal of biological macromolecules, 2012. 50(1): p. $250-256$.

[15] Dura, A., W. Błaszczak, and C.M. Rosell, Functionality of porous starch obtained by amylase or amyloglucosidase treatments. Carbohydrate polymers, 2014. 101: p. 837-845.

[16] Wu, C., et al., Development of biodegradable porous starch foam for improving oral delivery of poorly water soluble drugs. International journal of pharmaceutics, 2011. 403(1): p. 162-169.

[17] Marques, A., R. Reis, and J. Hunt, The biocompatibility of novel starch-based polymers and composites: in vitro studies. Biomaterials, 2002. 23(6): p. 1471-1478.

[18] Araújo, M.A., A.M. Cunha, and M. Mota, Enzymatic degradation of starch-based thermoplastic compounds used in protheses: identification of the degradation products in solution. Biomaterials, 2004. 25(13): p. 2687-2693.

[19] Boesel, L.F., J.F. Mano, and R.L. Reis, Optimization of the formulation and mechanical properties of starch based partially degradable bone cements. Journal of Materials Science: Materials in Medicine, 2004. 15(1): p. 73-83. 
[20] Santander-Ortega, M., et al., Nanoparticles made from novel starch derivatives for transdermal drug delivery. Journal of controlled release, 2010. 141(1): p. 85-92.

[21] Ali, A.E.-H. and A. AlArifi, Characterization and in vitro evaluation of starch based hydrogels as carriers for colon specific drug delivery systems. Carbohydrate Polymers, 2009. 78(4): p. 725-730.

[22] Neves, N.M., A. Kouyumdzhiev, and R.L. Reis, The morphology, mechanical properties and ageing behavior of porous injection molded starch-based blends for tissue engineering scaffolding. Materials Science and Engineering: C, 2005. 25(2): p. 195-200.

[23] Van Gaal, L.F., K.L. Van Acker, and I.H. De Leeuw, Repaglinide improves blood glucose control in sulphonylurea-naive type 2 diabetes. Diabetes research and clinical practice, 2001. 53(3): p. 141-148.

[24] Chatap, V., A. Karale, and P. Deshmukh, Fabrication of Specially Designed Novel Mould for Casting of Perindopril Erbumine Mouth Dissolving Film. Advances in Pharmacology and Pharmacy, 2013. 1(2): p. 58-67.

[25] Qin, Y., et al., Effect of morphology and pore structure of SBA-15 on toluene dynamic adsorption/desorption performance. Procedia Environmental Sciences, 2013. 18: p. 366-371.

[26] Ganesan, K. and L. Ratke, Facile preparation of monolithic $\kappa$-carrageenan aerogels. Soft matter, 2014. 10(18): p. $3218-3224$.

[27] El-Houssieny, B.M., L.F. Wahman, and N.M. Arafa, Bioavailability and biological activity of liquisolid compact formula of repaglinide and its effect on glucose tolerance in rabbits. tandem, 2010. 8: p. 10.

[28] CV, S., Text book of Physical Pharmaceutics. 1998.: p. p. 225-8.

[29] El Maghraby, G.M., et al., Self emulsifying Liquisolid tablets for enhanced oral bioavailability of repaglinide: In vitro and in vivo evaluation. Journal of Applied Pharmaceutical Science Vol, 2014. 4(09): p. 012-021.

[30] Grimm, W., Extension of the international conference on harmonization tripartite guideline for stability testing of new drug substances and products to countries of climatic zones III and IV. Drug development and industrial pharmacy, 1998. 24(4): p. 313-325.

[31] Zawar, L.R. and S.B. Bari, Preparation, characterization and in vivo evaluation of antihyperglycemic activity of microwave generated repaglinide solid dispersion. Chemical and Pharmaceutical Bulletin, 2012. 60(4): p. 482-487.

[32] Desai, N.S., D.M. Bramhane, and M.S. Nagarsenker, Repaglinide-Cyclodextrin complexes: Preparation, Characterization and in vivo evaluation of antihyperglycemic activity. Journal of Inclusion Phenomena and Macrocyclic Chemistry, 2011. 70(1-2): p. 217-225.

[33] Kannur, D., V. Hukkeri, and K. Akki, Antidiabetic activity of Caesalpinia bonducella seed extracts in rats. Fitoterapia, 2006. 77(7): p. 546-549.

[34] Yortsos, Y.C. and A.K. Stubos, Phase change in porous media. Current opinion in colloid \& interface science, 2001. 6(3): p. 208-216.

[35] Hu, Y., et al., 3D cubic mesoporous silica microsphere as a carrier for poorly soluble drug carvedilol. Microporous and Mesoporous Materials, 2012. 147(1): p. 94-101.

[36] $\mathrm{Vu}, \mathrm{X} . \mathrm{H}$. , et al., High-temperature synthesis of ordered mesoporous aluminosilicates from ZSM-5 nanoseeds with improved acidic properties. Nanomaterials, 2014. 4(3): p. 712-725.

[37] Kolakovic, R., et al., Spray-dried cellulose nanofibers as novel tablet excipient. Aaps Pharmscitech, 2011. 12(4): p. 1366-1373.

[38] Salonen, J., et al., Mesoporous silicon microparticles for oral drug delivery: loading and release of five model drugs. Journal of Controlled Release, 2005. 108(2): p. 362-374. 